\section{Propagating Diversity \\ through Active Dissemination}

\begin{abstract}
Katie A. Siek, University of Colorado at Boulder Kay Connelly, Suzanne Menzel, and Laura Hopkins, Indiana University
\end{abstract}

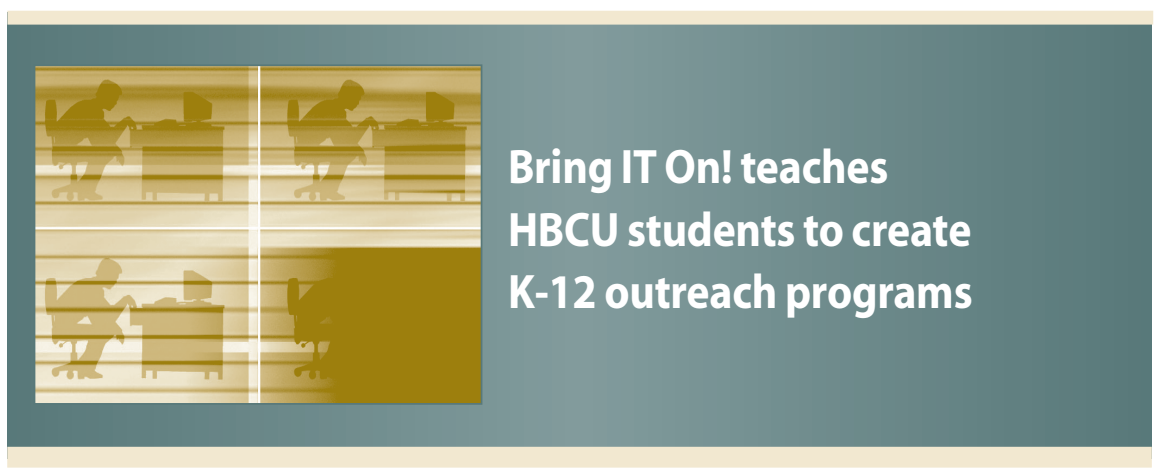

$\mathrm{f}$ imitation is the sincerest form of flattery, then the Women in Computing Group at Indiana University appreciates the compliments. Students from 10 historically black colleges and universities (HBCUs) recently visited IU to learn how to create a K-12 program based on Just Be, an IU outreach initiative that sends students to schools to challenge stereotypes about computer scientists (www. cs.indiana.edu/cgi-pub/wic/outreach/ index.php).

Our long-term goal is to build a pipeline of underrepresented students from high schools to graduate schools, with outreach programs at each of the 10 HBCUs serving as a crucial middle link. The glue that holds the pipeline together is a mutual and collaborative effort to develop outreach programs at each of the 10 HBCUs. The HBCUs will benefit from increased visibility as their students go out into the commu- nity to promote computer science as a discipline. The students will gain leadership experience as they develop and run their outreach programs, have opportunities to practice public speaking, and develop a broader understanding of research projects under way at their own schools. IU benefits by leveraging the diverse experience and knowledge of workshop participants to improve Just Be. cultures teaches skills that are valuable in today's global economy. By exposing students to opportunities at a research-driven institution, we hope to spark their imaginations and help them envision themselves as future researchers who advance the computer science field.

Disseminating participation-broadening activities is typically an afterthought. In these lean times, competition for students could cause schools
Working with people from other to be protective of successful recruiting strategies. However, we are eager to spread our outreach program to the HBCUs and support the development of 10 independent programs. We hope the resulting programs will achieve meaningful outcomes, from raising public awareness of the nature of computing to increasing the number of underrepresented students pursuing $\mathrm{PhDs}$ at research institutions.

\section{JUST BE}

Computer scientists have long been portrayed as socially challenged nerds, and their work characterized as dreary and highly technical. These negative attitudes are among the most-cited reasons for why many young people do not consider careers in computing.

To develop Just Be, we used the planned behavior theory ${ }^{1}$ as a framework for understanding and predicting motivational influences and to guide our strategy for changing those attitudes. Our program dispels the "geek myth," challenges students' attitudes about gender-appropriate careers, and exposes the social nature of computing and its positive impact on people's lives. We emphasize that diversity and inclusiveness within computing benefit society by creating better solutions and products.

Until this year, our presenters were female undergraduate and graduate students, allowing the audience to see women confidently and seamlessly interacting with technology. Albert Bandura's theory of self-efficacy suggests that vicarious experiences that social models provide are some of the best ways to create and strengthen self-efficacy. ${ }^{2}$ By choosing presenters who can serve as social models for the female students in the audience, Just Be subtly addresses the lack of self-efficacy among young girls.

The interactive Just Be presentation has three parts. During the initial segment, student presenters relate the early personal experiences that led them to study computer science in college. They explain what they are currently working on and describe activities they do for fun. The purpose is to depict the 


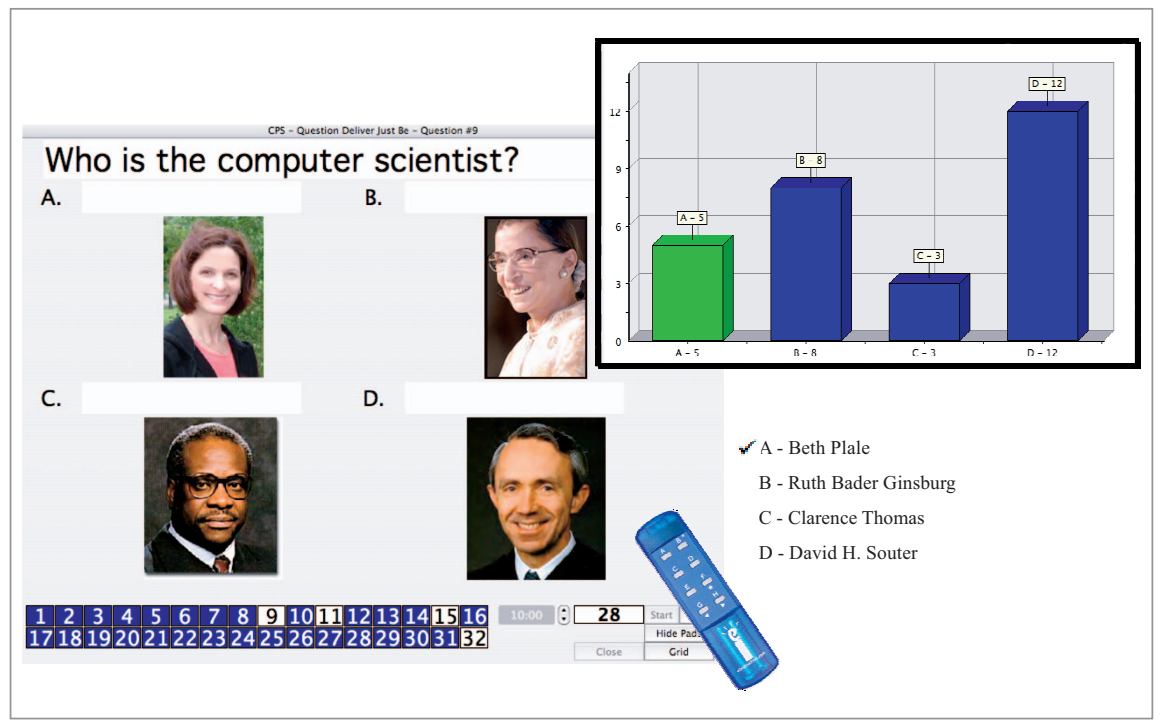

Figure 1.Sample Just Be poll. When asked to select the computer scientist from among a group of four people, only four of 28 respondents selected the correct individual.

presenters as well-rounded individuals celebrating empowering moments in their lives so they can be viewed as realistic role models with attainable goals. ${ }^{3}$

During the second phase, we confront the nerdy, white-male stereotype that hovers over computer science. We begin by asking audience members to close their eyes, envision a computing professional at work, and then describe what they see. Once audience members clearly articulate the stereotypes, we confront them by using voting modules in a sequence of poll questions, as Figure 1 shows.

The third phase covers fun and visually stimulating activities, including university projects, logic puzzles, and career and salary information. We emphasize cooperative projects involving a variety of people, such as IU's Discovering the Science of the Environment project (http://vis.iu.edu/ DSE/), and technology to help people, such as a mobile application to assist pediatric nurses in caring for their premature patients.

We are currently developing our assessment plan. We survey teachers who hear our presentation and use their comments to guide the everevolving content. To gauge the recruiting power of Just Be, IU will ask students enrolling in gateway courses in the School of Informatics if they learned about computing at IU by viewing a Just Be presentation. We plan to conduct focus groups with participants in after-school programs and clubs. A six-month follow-up with the same group members will let us determine if the presentation has a long-term effect on attitudes and selfefficacy.

Carnegie Melon University's Roadshow was our inspiration for Just Be (http://women.cs.cmu.edu/What/ Outreach/Roadshow/). Now, we would like the Just Be message to wind its way to other places, picking up steam among underrepresented students. We can only cover a limited amount of ground ourselves, which is why we have enlisted the help of the HBCUs.

\section{DISSEMINATION}

Necessity has led us to focus on K12 schools within Indiana for the foreseeable future. However, our goal to widely impact diversity in computer science extends well beyond our state boundaries. Thus, we have launched a major dissemination effort by

- providing information to $\mathrm{K}-12$ educators and then visiting schools to spread the word about computing, and

- teaching students from other colleges and universities about creat- ing an outreach program like Just Be.

We find that developing relationships with key individuals in regional $\mathrm{K}-12$ schools is one of our biggest challenges when targeting educators. We participate in educator enrichment programs attended by teachers, counselors, and administrators where we run workshops and arm educators with the information they need to get students excited about computing. These activities help us forge connections with K-12 schools and procure invitations to present Just Be at the educators' schools. ${ }^{4-7}$

For our efforts targeting other universities, we emphasize how to start an outreach program at conferences. ${ }^{8,9}$ We offer students, professors, and administrators ideas and strategies for creating an outreach presentation, finding a faculty champion, obtaining funding, and maintaining an outreach program. We exchange contact information with everyone who attends our talks and keep in touch with them to see if they went on to create a program at their school.

\section{Computing outreach in Indiana}

During continued contact with people who attended our "how to" presentations, we noticed that the first step was the most difficult. People could not find the time and energy to create a meaningful, exciting, and visually appealing outreach presentation. Most of the attendees asked us to visit and help them brainstorm about creating a presentation.

These pleas for help from people who were willing to create an outreach program, but needed an extra push, motivated us to organize the Computing Outreach in Indiana (COIN) workshop in April 2006 (www.cs. indiana.edu/cgi-pub/wic/outreach/ COIN.php). This one-day workshop drew administrators, faculty, and students from as near-by as Indianapolis, Indiana and as far away as Houston, Texas, to IU to learn about creating and implementing an outreach presentation. 


\section{Going beyond: Bring IT On!}

We created Just Be because qualified students, independent of gender, were not considering computing due to unfounded stereotypes. We emphasized women because they constitute less than 12 percent of the computer science undergraduates at IU. However, minorities make up less than 5 percent of IU's undergraduate computer science population. Unfortunately, these low numbers are not localized to IU. Underrepresented groups in other states also are not selecting computer science as a major. ${ }^{10}$

We want to present Just Be to more underrepresented groups, but Indiana's demographics work against us. As Figure 2 indicates, more than 85 percent of Indiana residents are white. Therefore, we decided to look outside Indiana to maximize our impact on underrepresented racial groups.

In October 2006, 11 female students and nine male students from 10 HBCUs attended a three-day Bring Information Technology On workshop at IU (www.cs.indiana.edu/bringiton). Figure 3 shows the logo for the "Bring IT On!" workshop, where attendees learned how to create their own outreach program and received information about different career paths after college.

University and corporate sponsorships paid for the students' expenses. The students networked with researchers and fellow students, learned about underrepresentation in computing and the professoriate, and created their own presentations to take back to their universities.

Just Be presenters showed participants how to develop and sustain a program while helping them decide what their respective presentations should contain to motivate their target groups of students. Professors and researchers discussed their projects and gave participants a glimpse of the endless possibilities for computing research, since many attendees do not attend researchoriented universities. Women and people of color were featured in the program and social events included members of IU's Black Student Union.

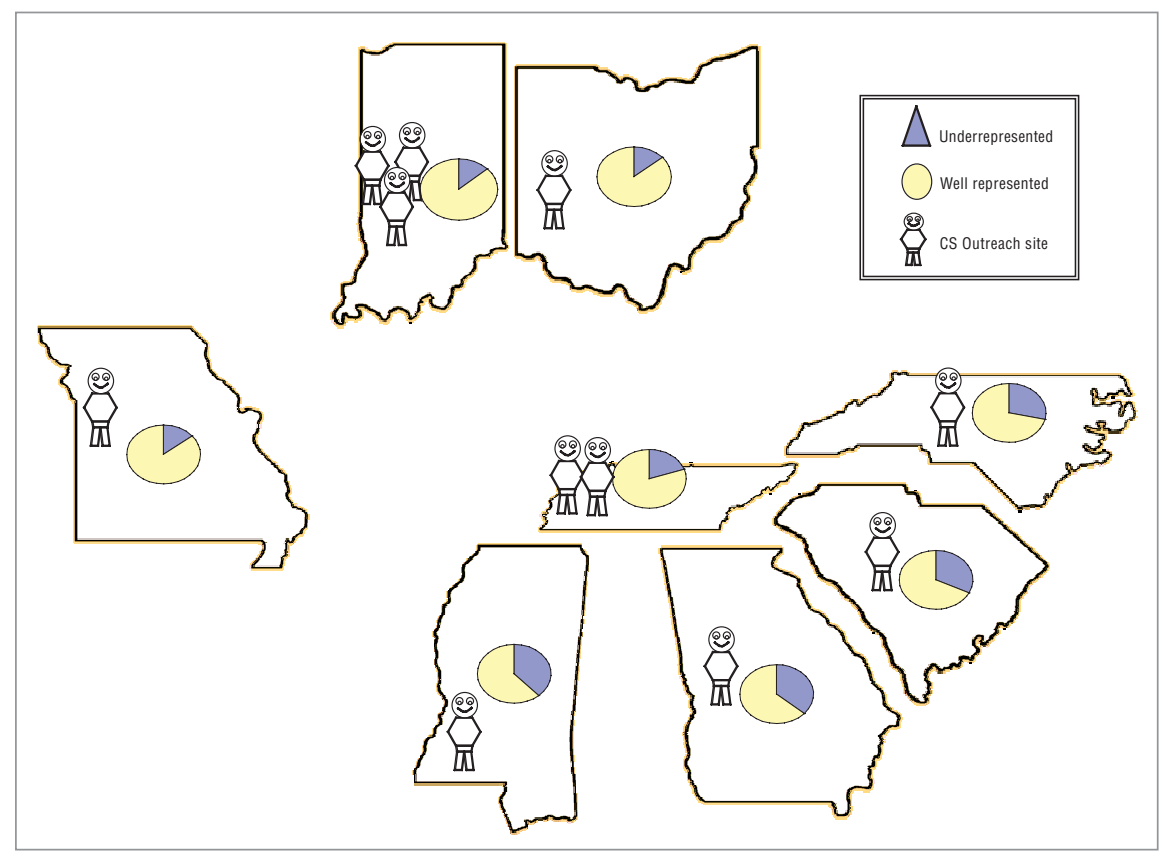

Figure 2. The Bring IT On! workshop assisted in spreading outreach to states where there is a larger percentage of underrepresented groups in the overall population.

While the participants learned how to create their own outreach program, we learned about what motivated these students to pursue computing. We plan to use their experiences to improve the IU computing and outreach programs. We administered questionnaires before and after the event to evaluate the workshop. The preworkshop questionnaire asked participants about their academic standing and their volunteer and research experience. The answers helped us customize the workshop content. The postworkshop questionnaire dealt with participants' satisfaction with the workshop and how they got involved in computing.

\section{Lessons learned}

From the COIN workshop, we learned that we needed to give participants more time and help when preparing their initial presentations. In particular, many participants knew little about the computing research and activities at their school. This led us to assign a Just Be volunteer to every school represented at Bring IT On! The volunteers compiled information about the schools in advance, giving participants valuable sugges-

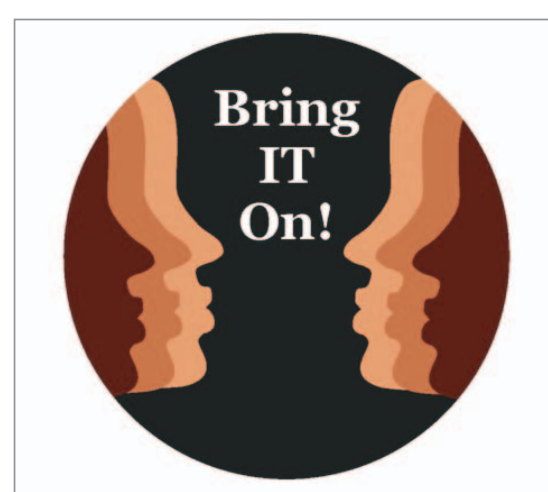

\section{Indiana University}

Figure 3. Bring IT On! logo. Workshop attendees learned how to create an outreach program and received information about different postcollege career paths.

tions as they constructed their slides.

The participants in both workshops gave their initial presentations and received valuable feedback from Just Be presenters and other workshop participants. This session gave the participants the opportunity to learn about each other and about other areas of computing that fellow attendees discussed in their presentations. 
The COIN followup interviews revealed that all the participants had identified a faculty champion and were well on their way to creating an outreach program. We are still analyzing the Bring IT On! postworkshop questionnaires, but the initial results are promising. When asked to rate the statement "I am going to start an outreach program at my institution" on a scale of 1 to 5 , with 5 being strongly agree, the participants scored it at 4.56 $(n=18$, sd $=0.70)$. We also learned that many HBCUs have a community service requirement; developing an outreach program will fulfill this requirement, giving the participants an added incentive for doing so.

As for our second goal of exposing Bring IT On! participants to research careers, of the 14 participants who completed both the pre- and postworkshop questionnaires, eight participants who had initially indicated they did not intend to pursue a PhD had changed their minds. Answering a freeform question, one student wrote, "I was surprised that they [people at the event] actually convinced me to attend graduate school."

Questionnaire responses also indicated that including people of color as social models in the program had a major impact. In response to which part of the program they liked best, one participant wrote, "Motivation speech by Dr. Gilbert; Someone who's professional and successful who looks like me ..."

We will maintain contact with people who attend our presentations and workshops like COIN and Bring IT On! to see if they successfully develop an outreach program and share lessons learned, advice, and other useful information with participants. We hope Bring IT On! will facilitate the development of meaningful long-term relationships with HBCUs so that we can work together to increase the number of undergraduate and graduate minority students in computer science.

0 ur Just Be outreach program's goal is to debunk common computing stereotypes and encour- age $\mathrm{K}-12$ students to consider a career in the exciting field of computing. We believe Just Be can encourage students to pursue computing because it is theoretically well-grounded in psychology literature.

Our outreach efforts are constrained by the cultural homogeneity at Indiana University and in the state as a whole, thus we disseminated our best practices to our colleagues from HBCUs during the three-day Bring IT On! workshop. In addition to helping other universities create an outreach program and get involved in their respective communities, the workshop also helped us understand more completely how best to encourage a broader group to join the computing profession.

By propagating our outreach program, we hope to realize an exponential gain so that, one day, all children can look at people in computing and see someone who looks like them.

\section{Acknowledgment}

This work was supported in part by NSF grant no. 0450373.

\section{References}

1. I. Ajzen and M. Fishbein, Understanding Attitudes and Predicting Social Behavior, Prentice Hall, 1980.

2. A. Bandura, Social Foundations of Thought and Action: A Social Cognitive Theory, Prentice Hall, 1986.

3. G.C. Townsend, “' $R$ \& R' for Women in Computer Science: Recruit and Retain,” J. Computing in Small Colleges, Nov. 1995, pp. 58-63.

4. K.A. Siek and A.L. Stephano, Invited talk at the Computer Science and Information Technology Symposium, Feb. 2005; www.iste.org/Content/NavigationMenu/ Professional_Development/Programming at_NECC/Symposia/Computer_Science/ 2005/February2/Speaker_Presentations/ Speaker_Presentations.htm.

5. M. Hart, J. Lewandowski, and K.A. Siek, "Fabulous and Functional Technology Finds for Teachers," Indiana Computer Educators, Jan. 2006; www. iceindiana.org.
6. J. Franko and K.A. Siek, "Demystifying and Degeekifying Computing Careers," Paul Munger Conf. for Youth-Serving Professionals, June 2006; http://munger. indiana.edu.

7. S. Menzel, “Doors to Diversity," TECS workshop, July 2006, Washington University; www.cse.wustl.edu/ grosspa/ summer_workshop.

8. K.A. Siek et al., "Breaking the Geek Myth: Addressing Young Women's Misperceptions about Technology Careers," Leading and Learning with Technology, Int'l Society for Technology in Education, Apr. 2006, pp. 19-22.

9. K.A. Siek et al., "Just Be: An Interactive Experience for K-12 Students," Proc. ASEE/IEEE Frontiers in Education (FIE 05), 2005, pp. F3H-15-F3H-16.

10. J.E. Gilbert, "Making a Case for BPC," Computer, Mar. 2006, pp. 83-86.

Katie A. Siek is an assistant professor in the Department of Computer Science at the University of Colorado at Boulder. Contacther at Katie.Siek@colorado.edu.

Kay Connelly is an assistant professor in the Computer Science Department at Indiana University. Contact her at connelly@indiana.edu.

Suzanne Menzel is a senior lecturer in the Computer Science Department at Indiana University. Contact her at menzel@indiana.edu.

Laura Hopkins is the outreach coordinator in the Computer Science Department at Indiana University. Contact her atlaubopki@indiana.edu.

Series editor: Juan E. Gilbert, Dept. Computer Science and Software Engineering, Auburn University; bpc@computer.org 